\title{
The Effect of Inoculation on Microstructure and Mechanical Properties of Ductile Iron
}

\author{
Mr. Bahubali B. Sangame ${ }^{1}$, Mr. Vasudev D. Shinde ${ }^{2}$ \\ ${ }^{1}$ (P. G. student at D.K.T.E.'s Textile and Engineering Institute, Ichalkaranji, 416115, India.) \\ ${ }^{2}$ (Associate professor at D.K.T.E. 's Textile and Engineering Institute, Ichalkaranji, 416115, India.)
}

\begin{abstract}
The current work proposes thermal analysis system for analysis of ductile iron solidification processing. The system consists of standard pouring cup with built in thermocouple. The thermocouple is connected to data logger system so as to store temperature data of solidification sequence. The ductile iron treatment consists of composition control, melt pre-treatment, magnesium treatment and inoculation processing. Even small change in processing can be monitored by thermal analysis and its effects on final microstructure and mechanical properties were studied. Along with test cups, the tensile test bars were also poured and analyzed for correlating the mechanical properties with solidification sequencing. The melting trials with varying amount of inoculation processing were conducted to study its effect especially on amount of nodule count, nodularity and amount of pearlite and ferrite phase. As the microstructure decides the final mechanical properties in ductile iron castings, the nucleation and proportion of these phases is of paramount importance during solidification. The thermal analysis of base metal and inoculated material can be effectively used for improving mechanical properties of ductile iron castings.
\end{abstract}

\section{Introduction}

Many of the steel components are replaced by ductile iron due to high strength to weight ratio and range of properties. The ductile iron provides good combination of strengths and ductility due to presence of spheroidal graphite. From a metallurgical view, ductile iron is one of the most complicated materials. During solidification several phases were nucleating and interaction of these different phases during growth is very complicated. The occurrence and distribution of these phases have major impact on the final mechanical properties of the casting. It is therefore interesting to understand how the different phases nucleate and grow during solidification in order to be able to control the casting process and achieve the right mechanical properties [1].

The commonly used mechanical properties for ductile iron are tensile strength, yield strength, percent elongation and brinell hardness. Because of the nominal and consistent influence of spheroidal graphite, the tensile properties and the brinell hardness of ductile iron are well related. The relation between tensile properties and hardness depends on structure of its base matrix. In the matrix, the softer ferrite gives higher ductility but lower yield strength than pearlite. Also the graphite morphology plays an important role and the more the graphite shape deviates from the ideal spherical shape, the lower is the ductility and strength [2]. The time after spheroidal treatment has significant effect on the elongation, but insignificant effect on the tensile strength and hardness of castings. Even small changes of the elements show significant increase or decrease in mechanical properties of ductile iron [3].

The chemical composition, melt treatment and cooling rate are important processing parameters which decide the final properties of ductile iron. The graphite nodule count and nodularity (deviation from spherical shape) and the amount of phases are to be controlled to achieve better combination of properties in ductile iron. Melt treatment consisting of modification and inoculation, in which initially magnesium treatment of the melt is done (for changing graphite shape from flake to spheroidal) and further inoculation (for increasing the nodule count or to suppress carbide formation) is must [4]. In case of hypoeutectic ductile iron,solidification proceeds by nucleation of austenite, and graphite spheroids nucleate on pre-existing austenite and grow in the interdendritic regions. In hyper eutectic melts, solidification starts with graphite nodules [5,6], which reduces the remaining carbon in the liquid, upon further cooling, the austenite grows dendritically and thus allowing new graphite spheroids in interdendritic regions[7]. Graphite nodules nucleate on small inclusions [8] but further growth solely depends on foreign particles or solutes which are added as inoculant [5].

Rare earth elements reduce the magnesium requirement for a particular set of nodule count and nodularity. As some of the magnesium measured is in the form of magnesium sulfide, final iron sulfur level affects the magnesium needed to result in nodular graphite. Maximum nodularity can be achieved by keeping magnesium residual just enough $(0.02 \%)$ will deteriorate the nodule shape from fully spheroicity [9]. Nodule count can be maximized by sound base iron melting practice and good inoculation practice. Nodule count and nodularity is affected by cooling rate. Thin section regions due to fast cooling results in better nodule shape than 
slowly cooled ductile iron for the same magnesium residuals. Larger sections require increased magnesium residual whereas late inoculation reduces the magnesium requirement[10]. In conjunction with this, current research work attempts to establish relationship between chemical composition, inoculation processing and pouring temperature of casting by solidification thermal analysis and comparing with experiments.

\section{Experimental Procedure}

To study the solidification process and its effect on mechanical properties, one needs to study heat transfer analysis of solidification sequences in ductile iron. The current study comprises of capturing solidification temperature data by built in thermocouples fitted in cup casting. Measuring and correlating the properties in castings by analyzing cooling curves. The cup is made up of shell sand, with $21 \times 21 \times 42 \mathrm{~mm}$ cavity (Electronite standard QC-4010) as shown in Fig.1. The weight of cup casting is $0.315 \mathrm{~kg}$ having modulus (volume/ surface area) of $7 \mathrm{~mm}$.

The melt charge consisting of $15-20 \%$ pig iron, 30-35\% Cold rolled steel scrap and remaining foundry returns is melted in $500 \mathrm{~kg}$ capacity coreless medium frequency induction furnace. The raw materials are tested for its chemical compositions by spectrometer analysis and are reported in Table 1.The molten metal was tapped in a preheated ladle containing Ferro-silicon-magnesium alloy of size $10-15 \mathrm{~mm}$ at the bottom covered with steel scrap. The tapping temperature of molten metal was $1450^{\circ} \mathrm{C}$. The inoculant is then added in the melt, while pouring directly in the stream for proper mixing (Fig.2 a). Inoculant of size 2 to $4 \mathrm{~mm}$ is added in molten metal stream so as to dissolve easily and should be dust free to avoid losses due to oxidation or thermal air currents. Total four ductile iron melts were poured using transfer ladle treatment method as shown in Table 2.

Table 1: Details of furnace charge mix along with spectroscopic analysis

\begin{tabular}{|c|c|c|c|c|c|c|c|c|c|c|c|}
\hline $\begin{array}{l}\text { Charge } \\
\text { materials }\end{array}$ & Amount & Size/shape & C & $\mathrm{Si}$ & $\mathrm{Mn}$ & $\mathrm{P}$ & $S$ & $\mathrm{Mg}$ & $\mathrm{Ca}$ & $\mathrm{Al}$ & $\mathrm{Ba}$ \\
\hline Pig iron & $65 \mathrm{~kg}$ & Briquettes & 4.13 & 1.91 & 0.14 & 0.075 & 0.025 & -- & -- & -- & -- \\
\hline $\begin{array}{l}\text { Foundry } \\
\text { returns }\end{array}$ & $135 \mathrm{~kg}$ & Gating & 3.68 & 2.21 & 0.18 & 0.010 & 0.026 & -- & -- & -- & -- \\
\hline Steel scrap & $300 \mathrm{~kg}$ & Punching & 0.038 & 0.001 & 0.302 & 0.025 & 0.008 & -- & -- & 0.04 & -- \\
\hline $\begin{array}{l}\mathrm{Fe}-\mathrm{Si}-\mathrm{Mg} \\
\text { alloy }\end{array}$ & $\begin{array}{c}1.8 \mathrm{~kg} / 150 \\
\mathrm{~kg} \text { ladle }\end{array}$ & $10-15 \mathrm{~mm}$ & -- & 47.50 & -- & -- & -- & 5.82 & 1.23 & 0.92 & -- \\
\hline Inoculant & $200 \mathrm{gm} / 50 \mathrm{Kg}$ & $2-4 \mathrm{~mm}$ & -- & 74.62 & -- & 0.035 & 0.004 & -- & 1.13 & 1.41 & 2.47 \\
\hline
\end{tabular}

(a)

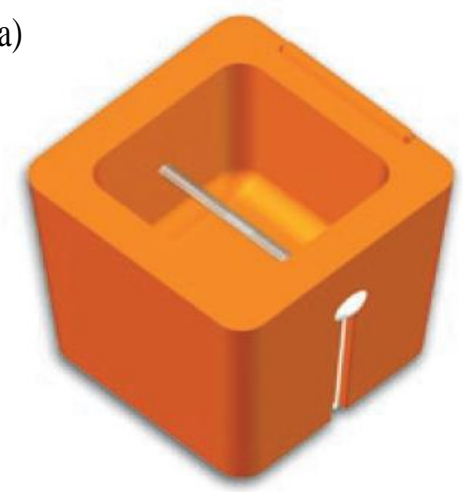

(c) (b)

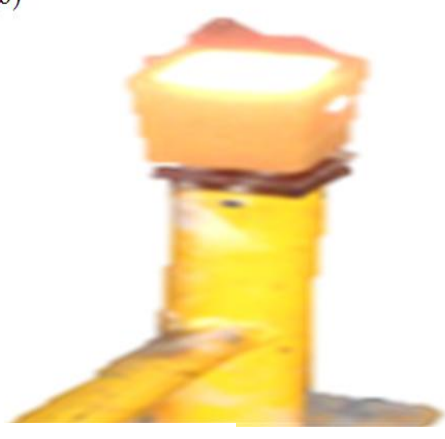

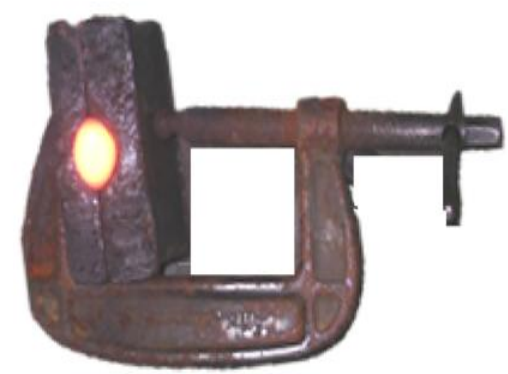


Fig.1: a) Ductile iron Non-Tellurium cup with standard Electronite-QC-4010, Cup stand b) poured cup and c) die assembly for sampling of chemical analysis test
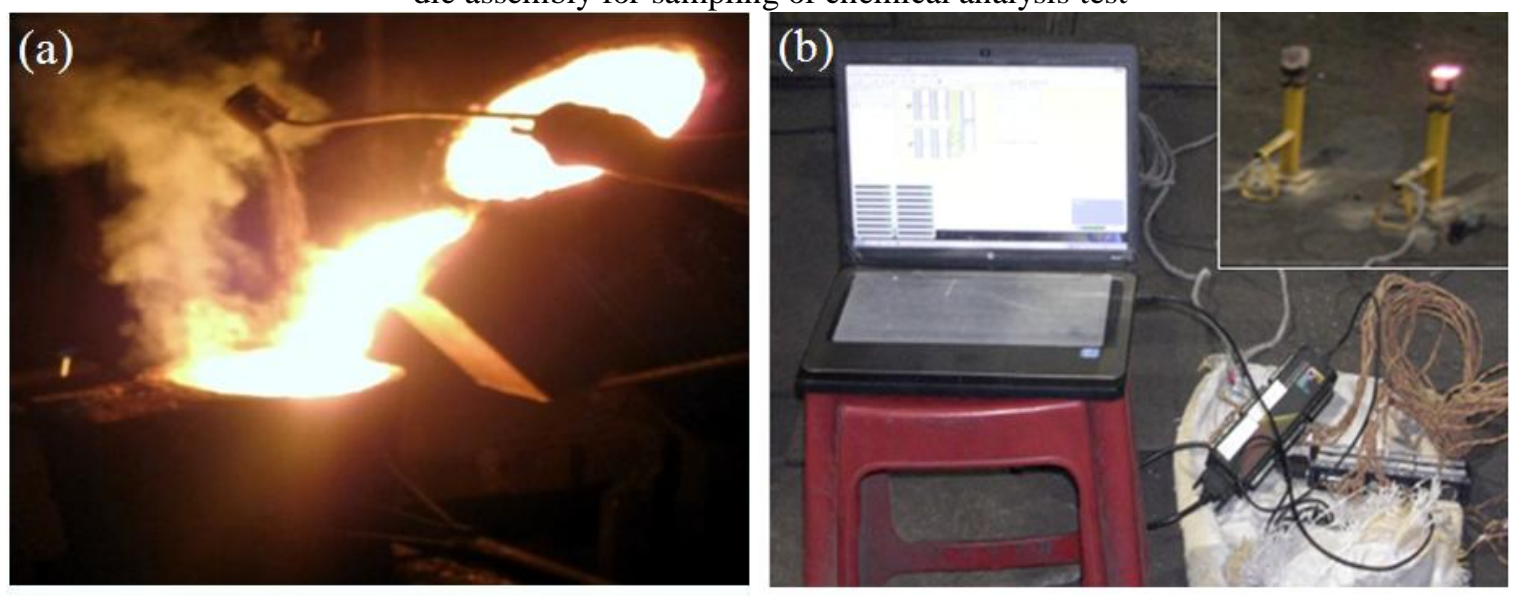

Fig.2: a) Stream inoculation process, b) Data acquisition system comprising of DAQ, thermocouples and pouring cup

While pouring, sample was taken from the melt for spectroscopic analysis. The treated iron was poured into shell molds for tensile test sample and cup castings for thermal analysis (Fig. 3). The pouring temperature recorded is $1380^{\circ} \mathrm{C}$. Similarly remaining melts were properly inoculated with each melt having varying amount of inoculant. In the varied inoculation trials, three cups were arranged in such a manner that pouring will be done in a sequential manner. $\mathrm{K}$ type thermocouples connected to each cup casting to capture temperature during solidification. ADAQ-3005 (MCC-USA) data logger for data acquisition synchronized with Desylab 12.0 software for analysis(Fig.2 b).Temperature time data thus captured can be further processed to plot cooling curves of individual melts processed differently. Metal samples are taken for spectroscopic analysis while pouring so as to measure final chemistry of the castings being poured. The final chemistry for each melt was determined using Spectrometer (Spectro-lab, M-9 model, German make). These chilled specimens were grinded on sand paper for performing the chemical analysis (Table 2).

Table 2: Chemical analysis of $0.4 \%, 0.6 \%$ and $0.8 \%$ Inoculated metal.

\begin{tabular}{|c|c|c|c|c|c|c|c|c|c|c|c|}
\hline Metal Treatment & $\mathbf{\%}$ & $\mathbf{\%}$ & $\mathbf{\%}$ & $\mathbf{\%}$ & $\mathbf{\%}$ & $\mathbf{\%}$ & $\mathbf{\%}$ & $\mathbf{\%}$ & $\mathbf{\%}$ & $\mathbf{\%}$ & $\mathbf{\%}$ \\
\hline Base Metal & $\mathbf{C}$ & $\mathbf{S i}$ & $\mathbf{M n}$ & $\mathbf{P}$ & $\mathbf{S}$ & $\mathbf{C u}$ & $\mathbf{A l}$ & $\mathbf{C a}$ & $\mathbf{B}$ & $\mathbf{C e}$ & $\mathbf{M g}$ \\
\hline A) 0.4\% Inoculation & 3.65 & 2.3 & 0.183 & 0.034 & 0.011 & 0.099 & 0.009 & 0.001 & 0.001 & 0.005 & 0.005 \\
\hline B) 0.6\% Inoculation & 3.65 & 2.5 & 0.173 & 0.028 & 0.012 & 0.10 & 0.023 & 0.001 & 0.001 & 0.011 & 0.035 \\
\hline C) 0.8\% Inoculation & 3.63 & 2.6 & 0.187 & 0.031 & 0.007 & 0.12 & 0.03 & 0.002 & 0.003 & 0.01 & 0.039 \\
\hline
\end{tabular}

\section{Results}

The experiments are conducted in ductile iron jobbing foundry and the results of thermal analysis, microstructural analysis and mechanical properties are presented as follows:

\section{1: Thermal Analysis}

The magnesium treatment is performed by transfer ladle process into $150 \mathrm{~kg}$ ladle. The base metal sample is taken after completion of charging and melting and poured into cup for thermal analysis as shown in Fig. 3 (a). The $\mathrm{Mg}$ treated metal is transferred into ladles of $50 \mathrm{~kg}$ and inoculated with A) $0.4 \%$ with $0.2 \mathrm{kgof}$ inoculant, B) $0.6 \%$ with $0.3 \mathrm{kgof}$ inoculant and C) $0.8 \%$ with $0.4 \mathrm{kgof}$ inoculant respectively (Table 2 ). The thermal analysis of metals with different inoculant is shown in Fig. 3(b). The thermocouples inserted in each cup casting records the thermal history of solidification process.

In the current experiments, the cooling curves are generated from solidification temperature history of solidifying base metal cup.It is observed that lower eutectic undercooled temperature $\left(\mathrm{T}_{\mathrm{EU}}\right)$ for base metal is 1119 ${ }^{\circ} \mathrm{C}$ and $\mathrm{T}_{\mathrm{ER}}$ temperature is $1132{ }^{\circ} \mathrm{C}$ which shows the larger undercooling effect which gives larger recalescence degree. The cooling curves generated from $0.4 \%, 0.6 \%$ and $0.8 \%$ inoculated cups, indicating the decreasing amount of recalescence as shown in Fig. 4(b). Larger the undercooling, more are chances of formation of undesirable carbides. The minute details of undercooling, recalescence and total solidification time values are used to correlate these solidifying details with final microstructure and mechanical properties. 

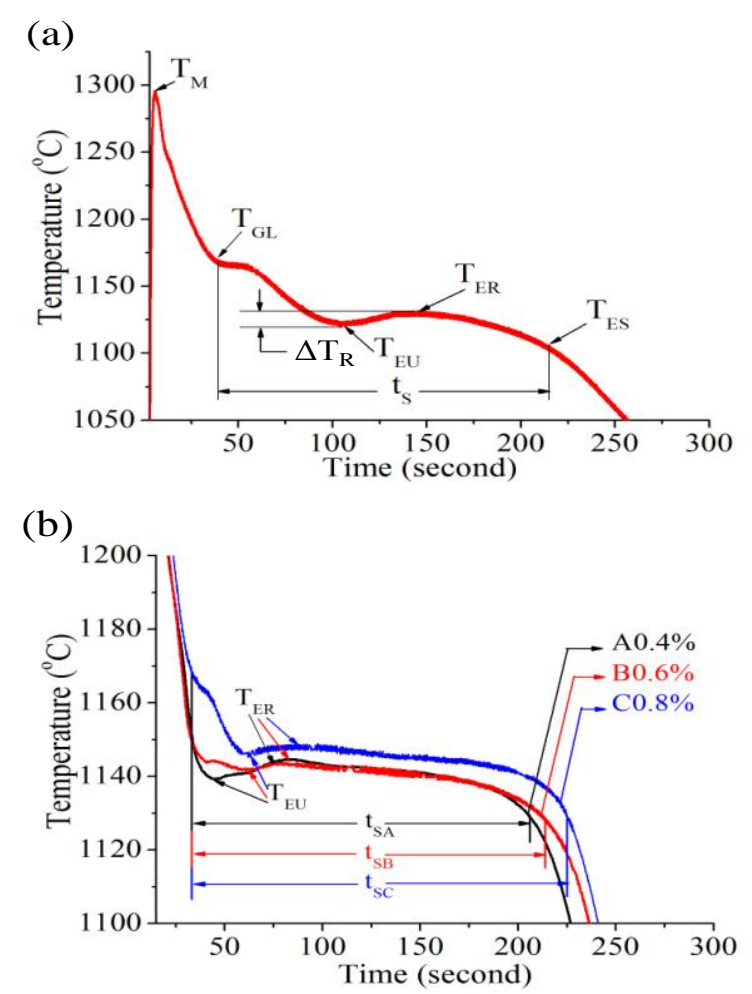

Fig.3:Cooling curve for a)base metal, b) Ductile iron with varying amount of inoculant

In the cooling curve (Fig. 3) $\mathbf{T}_{\mathbf{M}}$ - Maximum temperature of the melt $\left({ }^{\circ} \mathrm{C}\right) ; \mathbf{T}_{\mathbf{G L}}$ - temperature of graphitic liquidus $\left({ }^{\circ} \mathbf{C}\right) ; \mathbf{T}_{\mathbf{E U}}$-Temperature of eutectic undercooling $\left({ }^{\circ} \mathbf{C}\right) ; \mathbf{T}_{\mathbf{E R}}$ - Temperature of the graphitic recalescence $\left({ }^{\circ} \mathrm{C}\right) ; \Delta \mathbf{T}_{\mathbf{R}^{-}}$Recalescence $\left({ }^{\circ} \mathrm{C}\right) ; \mathbf{T}_{\mathrm{ES}}-$ Temperature at the end of solidification $\left({ }^{\circ} \mathrm{C}\right) ; \mathbf{t}_{\mathrm{S}}$-Total solidification time $(\mathrm{sec})$. When the liquidus temperature $\left(\mathrm{T}_{\mathrm{GL}}\right)$ is reached, the cooling curve shows a quasihorizontal plateau. This point means that, the heat losses are exactly balanced by the amount of heat of solidification. The length of the horizontal plateau is the total solidification time needed for the graphite to grow. However, the decrease of temperature continues till the lowest eutectic temperature $\left(\mathrm{T}_{\mathrm{EU}}\right)$. The solidification cooling curve normally shows undercooling at start of solidification. This undercooling is the driving force for nucleation. The period of nucleation isnormally short and is followed by an increase in the temperature giving a maximum temperature $\left(\mathrm{T}_{\mathrm{ER}}\right)$ shortly after the nucleation event. At eutectic temperature, simultaneously austenite and graphite gets precipitated from the liquid melt. After $\mathrm{T}_{\mathrm{EU}}$, the solidifying metal releases heat which shows overall increase in temperature, is referred as recalescence $\left(\Delta T_{R}\right)$ which is measure of difference between $\left(T_{E R}\right)$ and $\left(\mathrm{T}_{\mathrm{EU}}\right)$.

Table 3: Critical temperatures derived from thermal analysis

\begin{tabular}{|c|c|c|c|c|}
\hline \multirow{2}{*}{ Specific Temperature } & \multicolumn{4}{|c|}{ Temperature $\left({ }^{\circ} \mathrm{C}\right)$} \\
\hline & $\begin{array}{c}\text { Base metal } \\
\text { (uninoculated) }\end{array}$ & $\begin{array}{l}\text { A } 0.4 \% \\
\text { Inoculant }\end{array}$ & $\begin{array}{l}\text { B } 0.6 \% \\
\text { Inoculant }\end{array}$ & $\begin{array}{l}\text { C } 0.8 \% \\
\text { Inoculant }\end{array}$ \\
\hline Lower eutectic temperature $\left(\mathrm{T}_{\mathrm{EU}}\right)$ & 1119 & 1140 & 1141 & 1145.5 \\
\hline Eutectic Recalescence temp.(T $\left.\mathrm{T}_{\mathrm{ER}}\right)$ & 1132 & 1145 & 1144 & 1148 \\
\hline$\Delta \mathrm{T}_{\mathrm{EU}}=\mathrm{T}_{\mathrm{EU}}$ (Ino.) $)-\mathrm{T}_{\mathrm{EU}}$ (Unino.) & $-\overline{--}$ & 21 & 22 & 26.5 \\
\hline$\Delta \mathrm{T}_{\mathrm{R}}=\mathrm{T}_{\mathrm{ER}}-\mathrm{T}_{\mathrm{EU}}$ & 13 & 5 & 3 & 2.5 \\
\hline
\end{tabular}

The $\Delta \mathrm{T}_{\mathrm{EU}}$ is the difference in temperature of eutectic undercooling of inoculated and uninoculated iron and reported in Table 3. Also the recalescence is a measure of difference in $\mathrm{T}_{\mathrm{ER}}$ and $\left.\mathrm{T}_{\mathrm{EU}} \Delta \mathrm{T}_{\mathrm{R}}=\mathrm{T}_{\mathrm{ER}}-\mathrm{T}_{\mathrm{EU}}\right)$, Where $\mathrm{t}_{\mathrm{SA}}, \mathrm{t}_{\mathrm{SB}}$ and $\mathrm{t}_{\mathrm{SC}}$ are the eutectic solidification times for $0.4 \%, 0.6 \%, 0.8 \%$ inoculated metals in seconds. In the current experimental conditions, the difference between the $\mathrm{T}_{\mathrm{EU}}$ temperatures of inoculated and uninoculated iron $\left(\Delta \mathrm{T}_{\mathrm{EU}}\right)$ was observed in the range of $21-26.5^{\circ} \mathrm{C}$. A higher $\mathrm{T}_{\mathrm{EU}}$ value indicates that metal is more resistant to chill than with a lower $T_{E U}$ value. The highest eutectic temperature $\left(T_{E R}\right)$ is attained as a result of increase in temperature because of the release of inherent heat called latent heat. The recalescence $\left(\Delta T_{R}=T_{E R}-T_{E U}\right)$ reflects the amounts of austenite and graphite that precipitate during the first part of eutectic freezing. Too high recalescence might be harmful especially in soft moulds, as the volume expansion is high and might increase the size of the mould cavity. The ideal recalescence depends on casting material and its modulus. In well inoculated 
ductile iron casting, less than $5^{\circ}$ Crecalescence is preferred. Lower level of recalescence will depict high efficiency of inoculants and the risk for micro shrinkage and porosity will be reduced.

(a)

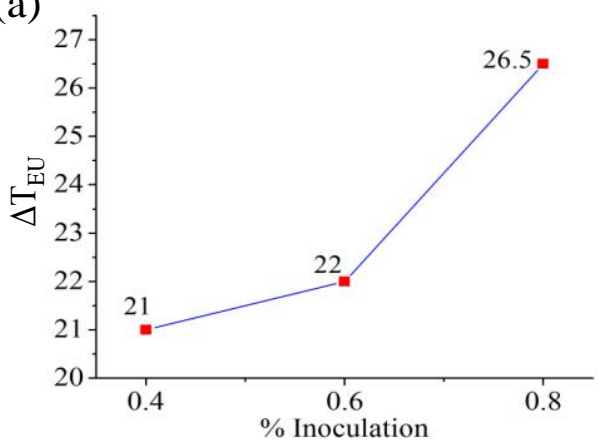

(b)

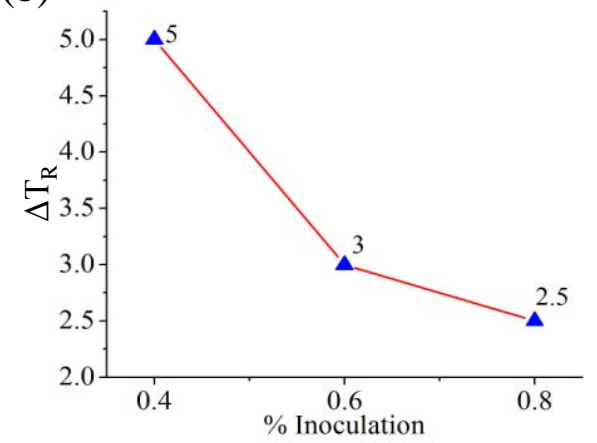

Fig. 4:a) Undercooling difference between inoculated and un-inoculated ductile irons b) Recalescence degree of inoculated ductile iron

\section{2: Microstructure analysis}

The samples for microstructural observation were taken from the center of the casting and polished properly. The samples were etched with $2 \%$ Nital (2\% concentric Nitric acid and $98 \mathrm{ml}$ Methylalcohol). Then optical micrographs were taken with a $35 \mathrm{~mm}$ camera attached to a Leintz microscope.

Table 4: Analysis of microstructure in inoculation varied ductile iron samples

\begin{tabular}{|c|c|c|c|}
\hline Inoculation amount & \% Nodularity & Nodule count $\left(/ \mathrm{mm}^{2}\right)$ & $\%$ Ferrite \\
\hline $0.4 \%$ & 84 & 205 & 88.43 \\
\hline $0.6 \%$ & 90 & 264 & 90.24 \\
\hline $0.8 \%$ & 95 & 291 & 94.09 \\
\hline
\end{tabular}

The polished samples after metallographic analysis were put under Image Analyzer (Make-ProMetal-11) to investigate the nodule count, nodularity and percentage of ferrite and pearlite content in the cast samples (Fig. 5). A microstructure analysis result of $0.4,0.6$ and $0.8 \%$ inoculated metal showing increase in nodule count, nodularity and ferrite \% with amount of inoculation (Fig. 6). The nodule count increases from 205 to 291, \% nodularity from 84 to 95 and \% ferrite from 88 to $94 \%$ with increase in inoculation from 0.4 to $0.8 \%$ respectively (Table 4).
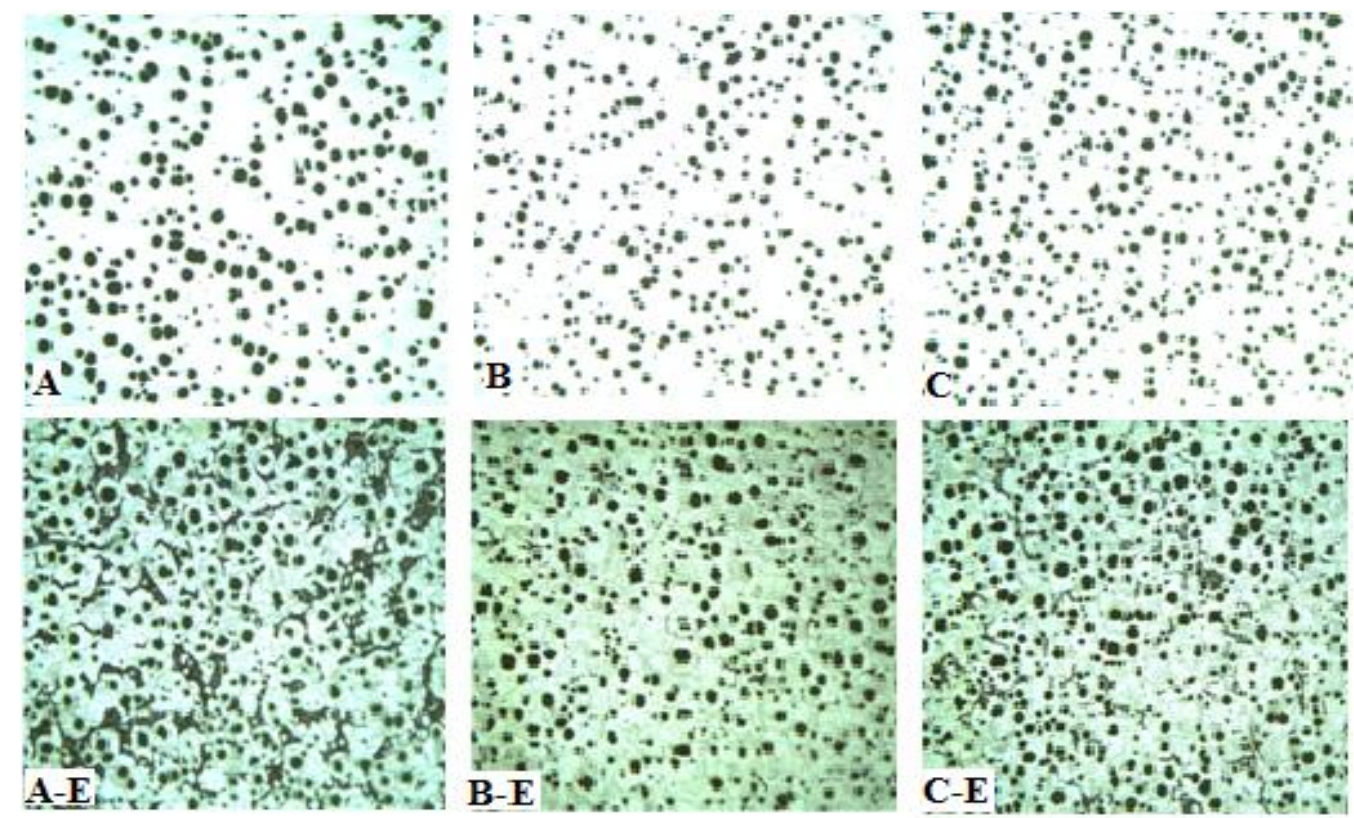

Fig.5:Microphotographs of ductile iron samplesindicatingunetched (A, B and C) and etched with Nital(A-E, BEandC-E)inoculated with $0.4 \%, 0.6 \%$ and $0.8 \%$ respectively 
(a)

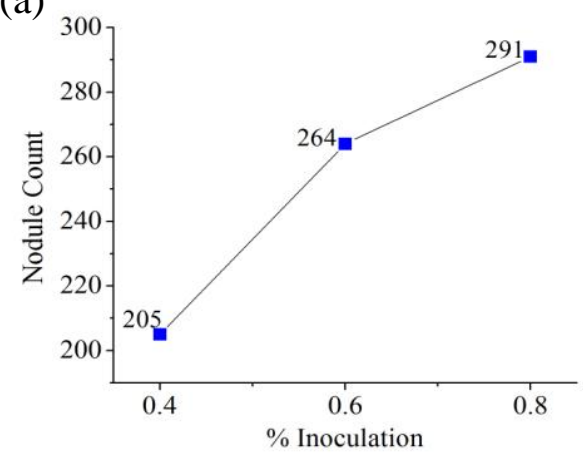

(b)

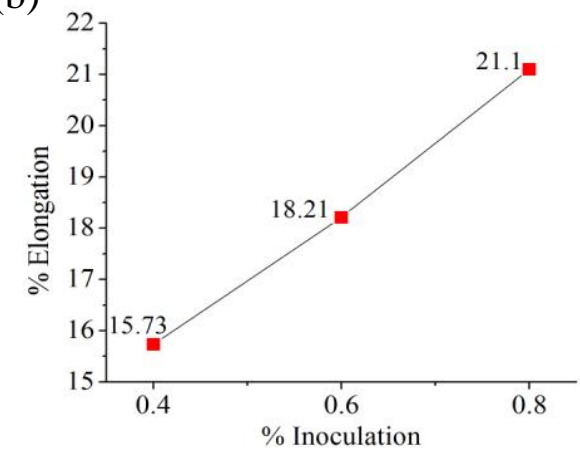

Fig. 6:a) Effect of \% inoculation on nodule count. b): Effect of \% inoculation on \% elongation.

\section{3: Mechanical properties}

The ductile iron inoculated metal in also poured into the shell mould of tensile bar as shown in Fig. 7 (a) so as to prepare tensile sample as per ASTM E-24 standard Fig.7 (b). After machining of tensile cast bars, these samples are tested for tensile strength and results are reported in Table 5. The thermocouples inserted in each cup casting records the thermal history of solidification process. From each melt the tensile bars are poured and machined to prepare specimens for conducting tensile test as per ASTM standard E-24. The tensile strength and elongations results measured using MTS machine were reported in Table 5. The tensile strength decrease from 483 to $421 \mathrm{MPa}$ with increase in elongation from 15.7 to $21 \%$ with increase in addition of inoculant from 0.4 to $0.8 \%$ respectively.

(a)

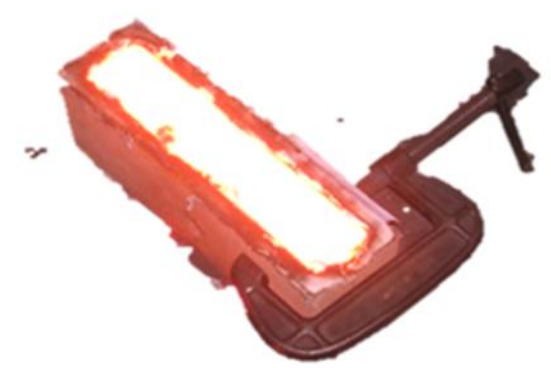

(b)

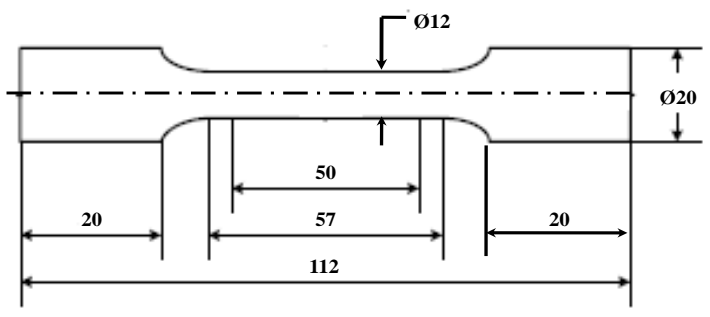

Fig. 7: (a) Test bar mould poured with molten metal, and b) Specifications of tensile specimen as per ASTM E24

Table 5: Effect of inoculation variation on tensile strength of ductile iron

\begin{tabular}{|c|c|c|}
\hline Inoculation amount & \% Elongation & Tensile strength (Mpa) \\
\hline $0.40 \%$ & 15.73 & 482.95 \\
\hline $0.60 \%$ & 18.21 & 452.74 \\
\hline $0.80 \%$ & 21.1 & 420.85 \\
\hline
\end{tabular}

\section{Discussion}

Experiments have been performed on ductile iron melts with base metal composition and inoculated metal with varying amount of inoculants. The thermal history of solidification processing is being recorded which will be used to correlate microstructural evolution of the solidified structures and mechanical property measurements. In case of un-inoculated (base) metal, the recalescence $(\Delta \operatorname{Tr})$ is $13{ }^{\circ} \mathrm{C}$, which indicates need of larger driving force for the solidification process. However, the higher undercooling before recalescence increases the risk of formation of carbides in the solidified structure. In case of inoculated metal, the recalescence value is within $5{ }^{\circ} \mathrm{C}$. The increase in amount of inoculation shows decrease in recalescence value. The basic function of inoculation is to increase nucleation sites, thereby reducing undercooling and promoting the graphite nucleation which minimizes the risk of formation of hard eutectic carbides. The cooling curves of inoculated metal reveal that, the eutectic undercooling temperature $\left(\mathrm{T}_{\mathrm{EU}}\right)$ increases with increase in inoculation. 
The solidification times of melts $\mathrm{A}$ to $\mathrm{C}\left(\mathrm{t}_{\mathrm{SA}}, \mathrm{t}_{\mathrm{SB}}\right.$, and $\left.\mathrm{t}_{\mathrm{SC}}\right)$ increases with increased amount of inoculant addition. Nodule count, expressed as the number of graphite nodules $/ \mathrm{mm}^{2}$, also influences the mechanical properties of ductile iron, although not as strongly and directly as graphite shape. Generally, high nodule count indicates good metallurgical quality, but there is an optimum range of nodule count for each section size of castings, and nodule count in excess of this range may result in a degradation of properties. Thermal analysis cups are designed such that, it weighs 315 gms having modulus of $7 \mathrm{~mm}$, offers cooling rates such that it gives optimum combination of tensile strength and ductility, which is followed as guideline for making casting of nearby modulus.

\section{Conclusion}

The experiments were conducted on ductile iron with varying amount of inoculant. The cup thermal analysis can be effectively used for measuring performance of amount of inoculant on solidification of ductile iron castings. Within the experiments conducted, the following conclusions were highlighted:

- Nodule count influences the pearlitic content of as-cast ductile iron. Increasing the nodule count decreases the pearlite content and tensile strength and increase in \% elongation.

- Increasing the nodule count improves ductility which reduces the tendency of formation of chill carbides.

- Matrix consistency is influenced by nodule count. Increasing the nodule count produces a finer and more homogeneous microstructure. This refinement of the matrix structure reduces the segregation intercellular harmful carbides, pearlite or degenerated graphite.

- Inoculation practices used to improve nodule count often make the nodules more spherical. Thus, high nodule count is generally associated with improved nodularity offering increase in toughness.

- The increase in amount of inoculation decreases the recalescence and amount of undercooling improving overall properties of ductile iron.

\section{Acknowledgement}

Author gratefully acknowledges the assistance of S. S. Industries, Ganeshnagar,Ichalkaranji for supporting melting trials, thermal analysis and microstructure analysis and M/s Suyash enterprises, Pune for supporting thermal analysis for providing thermal analysis cups.

\section{References}

[1]. O. SeiduS., I. Riposan, "Thermal analysis of inoculated ductile irons”, U.P.B. Sci. Bull., Series B, 73(2), (2011) pp. $241-253$.

[2]. D. Sparkman, "Using thermal analysis practically in iron casting," Modern casting. (1994).

[3]. S. Bockus, A. Dobrovolskis "Peculiarity of Producing Ferritic Ductile Iron Castings", Materials Science (Medziagotyra), 10, 1, (2004) pp. 3-6.

[4]. Rio Tinto Iron and Titanium, "Ductile Iron Databook for Design Engineers", Monreal, (1999), pp. 250

[5]. J. Campbell in Castings Principles, the "New Metallurgy of Cast Metals Elsevier", Amsterdam. (2004).

[6]. M. C. Flemings, in "Solidification Processing", McGraw-Hill Book Company, New York, (1974) pp. 423.

[7]. T. Skaland, in proceedings of the AFS cast iron, schaumburg, Illinois, (2005) pp. 29-30.

[8]. G.L. Rivera, R.E. Boeri, and J.A. Sikora, AFS Transactions, (2003) pp. 111, 979.

[9]. J.D. Mullins, in manual of Sorelmetal, Technical services, Rio Tinto Iron and Titanium, (2006).

[10]. T. Skaland, Ø. Grong and, T. Grong, "Metallurgical and Materials Transactions" A, 24(A), (1993), pp. 2321. 